University of Wollongong

Research Online

Faculty of Education - Papers (Archive)

Faculty of Arts, Social Sciences \& Humanities

April 2004

\title{
"Being Healthy": The discursive construction of health in New Zealand children's responses to the National Education Monitoring Project
}

Jan Wright

University of Wollongong, jwright@uow.edu.au

L. Burrows

University of Wollongong

Follow this and additional works at: https://ro.uow.edu.au/edupapers

Part of the Education Commons

\section{Recommended Citation}

Wright, Jan and Burrows, L.: "Being Healthy": The discursive construction of health in New Zealand children's responses to the National Education Monitoring Project 2004.

https://ro.uow.edu.au/edupapers/9 


\title{
"Being Healthy": The discursive construction of health in New Zealand children's responses to the National Education Monitoring Project
}

\author{
Jan Wright*, University of Wollongong, Australia \\ Lisette Burrows, University of Otago, New Zealand
}

\begin{abstract}
In this paper we examine the discursive resources which year 4 and year 8 students draw on to construct meanings for health. Drawing on students' responses to tasks in the New Zealand National Monitoring Project (Crooks \& Flockton, 1999) we examine what students have to say about health, speculate on where these responses have come from, and on the implications of these for health education pedagogy. The students' responses indicate that they are well-versed in "healthism" discourses which link practices like eating, exercise, smoking, drinking and taking drugs with "health". The students' responses also point to the construction of health knowledge as certain and static. Relatively little attention is paid to the social, cultural, economic or political contexts of people's lives. Indeed, the "typical" responses clearly point to the dominance of white, middle class values about health and fitness promoted in New Zealand society. We conclude by posing several questions generated for educators.
\end{abstract}

\section{Introduction}

Current school-based health education programmes and health promotion strategies work primarily on the premise that as young people become more knowledgeable about health they will behave in ways which lead to their own better health and well-being (Seedhouse, 1997). This position - that knowledge leads to changes in behaviour-has been widely contested (Lupton, 1999). While we would support a position that knowledge may not lead to the behaviours desired by those producing the knowledge in school contexts, we would argue that this knowledge still has an effect. Following Foucault, we argue that knowledge defines subjects, and that discursive practices have material effects (Bacchi, 2000: 52). In this paper we are concerned with the kinds of knowledge being produced in school contexts and the resources available to students to make sense of their health and their lives.

Foucault's linking of power with the production of knowledge is also central to our position. The notion that power is exercised rather than held, and that power can be productive as well as repressive, generates questions about how power is exercised in the construction of knowledge

\footnotetext{
${ }^{*}$ Correspondence: Jan Wright, Faculty of Education, University of Wollongong, Wollongong, NSW 2522, email: jwright@uow.edu.au
} 
about health. For instance, what kinds of health knowledge and practices are legitimised and how are children constituted and positioned as healthy or unhealthy in discourses of health? Foucault (1988) calls the processes whereby individuals are led to effect changes to their thoughts, conduct and bodies in pursuit of an ideal state, "technologies of the self". We draw on this concept to inform our analysis of how children are encouraged to "effect by their own means or with the help of others a certain number of operations on their own bodies and souls" (Foucault, 1988: 15) in order to attain status as a "healthy" person.

From this position we are interested in the particular understandings/meanings about health that are produced in schools and related contexts and the ways in which these are used as resources for understanding health by young people. We take as given that "health" is not a static or universal concept (Davis \& Dew, 1999), although it may be constructed as such. We are interested in questions such as how is it defined, by whom, for whom and with what effects? How does a specific notion of health predict particular content and pedagogies for teaching about health?

The approach taken in this paper is to explore these questions through students' responses to tasks in the New Zealand National Monitoring Project (NEMP) (Crooks \& Flockton, 1999) which were designed to determine students' understandings of what it means to be a "healthy person" and what one needs to do to become a "healthy person". We start from a position that in responding to the tasks students are drawing on knowledge derived from a range of cultural/textual resources - written, electronic, and interpersonal-and also embodied experiences. While textual resources are what most interest us, it is clear that some of the students' responses are also derived from significant personal experiences.

Our hypothesis is that the most likely textual resources are those produced within school, media and family contexts. Given the ubiquitousness of messages about health, one of our questions was how do we recognise where knowledge about health has come from? The answer to this lay in the consistency and specificity of certain kinds of knowledge across schools, regions, genders, ethnicities and both between and within age groups produced in the students' responses. Such specificity suggests a consistent set of messages, most likely but certainly not only, promoted in school-based programs of work. The ways in which such messages already had purchase in year 4 also suggest the consistency between school-based messages and those produced in the media and the home.

Our analysis of the students' responses does not assume that these are any more than textual reconstructions of knowledge. We do not assume that because children say that eating lots of fruit and vegetables is important to being a healthy person that they necessarily eat lots of fruit and vegetables. The questions are not only what meanings of health are drawn on but also what is absent in the students' responses to the tasks? What possibilities for alternative versions of health are present and what orientations to health knowledge do the students seem to exhibit? Poststructuralist and critical theory interrogations of the meanings of health and the ways in which these are promulgated also make it possible to suggest possible effects of particular meanings of health for children and for people more generally.

\section{Background to project}

In 1993, New Zealand's National Education Monitoring Project (NEMP) was set up. The project had the task of assessing and reporting on the achievement of New Zealand primary school children in all areas of the school curriculum over four-yearly cycles. The purpose of the national monitoring was two-fold. Firstly, "to meet public accountability and information requirements by identifying and reporting patterns and trends in educational performance”, and 
secondly, "to provide high quality, detailed information which policy makers, curriculum planners and educators can use to debate and review educational practices and resourcing” (Crooks \& Flockton, 1999: 6). In 1998, children's skills, knowledge, perceptions and attitudes relating to health and physical education were assessed at two class levels: year 4 (8-9 year-olds) and year 8 (12-13 year-olds), and the results were published in a 1999 report (Crooks \& Flockton, 1999). The ethnicity of students was identified as part of the demographic data collected, allowing broad trends in Maori and non-Maori ${ }^{1}$ achievement to be examined. The assessment tasks addressed four spheres of the New Zealand health and physical education curriculum: Personal health and physical development; Relationships with other people; Movement skills; and Healthy communities and environments.

Part of this national assessment program involved students writing and speaking about their understanding of health and fitness. In this paper we are specifically interested in the students' responses to two tasks (discussions of other tasks related to fitness are available in Burrows, Wright \& Jungersen-Smith, 2001):

- Being Healthy - a one-to-one task which asks students to specify what things they would need to do to be really "healthy” (e.g. “eat well”; “drink lots of water”; “run every day”);

- Healthy Person - a team activity where four children work together to identify the key components of a healthy person. In addition, children independently record their ideas about what comprises a healthy person.

We need to be very clear under what conditions the data was collected. These were not openended conversations but responses to tasks designed to assess students' understanding of particular concepts as they are presented in the school curriculum. An ideal outcome was a close match between students' responses and curriculum intentions as expressed in the syllabus. The students presumably understood this or at least understood that from the knowledge and understandings they had available to draw on, some would be valued in school contexts and some not. This is evident in the responses and particularly in the changes in the responses from year 4 to year 8 and is indeed one of the points we want to make in this paper. The year 8 students are clearly drawing on responses from formal sets of knowledge which have been developed in the context of the currently endorsed knowledge about health, physical activity and fitness. The year 4 students have fewer formal/school-based resources on which to draw and tended to draw on home and media experience/texts for their responses to tasks.

For this current project, the authors analysed all the responses to the health and fitness tasks using the qualitative software package, NUD•IST to code responses and elements of responses on the basis of demographics, questions and sub-themes. This enabled the qualitative organization of responses into categories as they referred to concepts such as "appearance", "weight", "exercise" and so on. It also provided the means to quantify the proportion of responses in such categories on the basis of demographics such as year, school, gender and ethnicity. While we have not reported on the descriptive statistics for each category in this paper-we do not believe the main argument of this paper rests on this-such quantifications allow us to speak with some credibility when making claims about typicality and differences between year groups.

\section{Meanings of health}

Schools have long been recognised as institutions that do disciplinary work (Gore, 1993). Technologies of power such as normalisation, classification and exclusion (Gore, 1995), together 
with the arrangement of bodies in space, choice of curriculum materials and assessment modes shape students in particular ways. When the disciplinary practices of schools are linked with the "technologies of the self" associated with health, a powerful combination for producing particular ways of thinking and living results. As Foucault observed, medicine is one general technology of health, yet many other technologies have now emerged, technologies that target the individual's management of his/her own relationship to risk (Petersen, 1996) and link risk to notions of choice, responsibility and blame. While recent shifts towards what is termed a public health model (Davis \& Dew, 1999), ostensibly support less individualised and medicalised notions of health, the principle of personal responsibility for one's health is still a powerful and pervasive discourse. For example, contemporary frameworks that regard individuals as being perpetually "at risk" from potential "hazards" position modern citizens as responsible for protecting themselves from these lifestyle, environmental and interpersonal risk factors by purposively living a "healthy lifestyle" (Castel, 1991; Lupton, 1995; Petersen, 1996).

It is the assumption that risks can be managed through human intervention that has informed physical education discourses which link health with fitness, as well as the messages concerning sexual activity, drug use and other "adolescent issues", which have increasingly been drawn into the subject domain of physical and health education in schools since the 1980s (Kelly, 1998). Despite considerable anecdotal and research evidence suggesting deterrent programmes are doomed to failure in the adolescent market (Kelly, 1998), an assumption that "knowledge changes attitude which in turn changes behaviour" remains embedded in much of the curricula content and pedagogy of school physical education. This presumption ultimately has consequences for the way children are constructed as knowing or ignorant subjects in the course of their school study of physical education and health subjects.

In the context of public health and school-based health and physical education the dominant discourses of health have defined health in terms of risk factors identified by medical and more recently social (epidemiological) research and as achievable through the efforts of individuals. Kirk and Colquhoun (1989), Tinning (1985) and Sparkes (1989) are among contemporary physical education theorists who have examined the implications of a discourse of healthism for physical educators' work in schools. They point to the way that a healthism discourse inevitably positions the body centrally in the creation of health, linking deliberate physical exercise and a range of other bodily practices with the attainment of health, where health and well-being is taken to be indicated by body shape, size and weight (Kirk \& Colquhoun, 1989). They argue that health-based physical education in schools explicitly supports a discourse of healthism by promoting normalised conceptions of the ideal body, by a singular emphasis on the role of vigorous physical activity in achieving health, and by stressing an individual's attitude towards physical activity as a primary predictor of health.

School-based health education programmes thus become responsible for providing "accurate" and "factual" information on the basis of which students can make "informed health choices". This information is derived predominately from the medical, psychological and biophysical sciences-disciplines that have the imprimatur of "expert" knowledge and consequently present health knowledge uncritically as certain, universally applicable and uncontestable. Such certain knowledge supported by bio-medical research produces "reliable facts" on which health behaviour can be based. At the same time, health is increasingly being revealed as a site of uncertain knowledge (Davis \& Dew, 1999; Petersen, 1996). What constitutes a healthy lifestyle is reconstituted regularly as new research is reported by the media. For instance, recommendations for daily physical activity regimens have shifted both in terms of intensity and duration, red meat is enjoying a resurgence as a "healthy" food in some western countries, and the amounts of wine one can drink seem to vary from one moment to the next. 
Clearly health is a term used in diverse ways, linked to particular value systems, world views and sociopolitical, economic and cultural contexts. What sense children make of the diversity and oft-times contradictory ways in which health is represented to them is an under-researched topic. Mayall's (1994) book, Children, Health and the Social Order, is an insightful study of young British children's constructions of health and Williams and Bendelow's (1998) article, "Malignant bodies: children's beliefs about health, cancer and risk", provides important information about how young British children conceive of being "healthy" and "unhealthy". Apart from these two key studies, there is very little empirical work that directly seeks to understand what it means to children to be "healthy" or "unhealthy". Our study is an attempt to | begin to answer questions about how children construct health in a New Zealand context.

\section{| Health discourses in media, syllabi and Life Education texts}

At the time of the National Education Monitoring Project assessment, health and physical education were two distinctly separate curriculum areas, each with its own syllabus and set of teaching resources. The 1985 Health Education Syllabus (Department of Education, 1985) and accompanying Health Education Trial Units for Designated Schools (Department of Education, 1986/1987) were guiding documents for the teaching of health in New Zealand. The 1987 Physical Education Syllabus of Physical Education and its companion booklet, "Physical Education: Guidelines for Success” (Department of Education, 1987), supported physical education teaching. As the formalised and mandated statements of what should be taught and how that subject matter should be taught in schools, these syllabi are crucial sources for analysis. Even though syllabi are not necessarily taken up as intended by curriculum writers, they nevertheless point to the professional priorities of health and physical educators at that time and provide a blueprint for "practice". A range of government and private agency resources supplemented these key documents in both areas. For example, the Hillary Commission for Sport and Leisure has produced several resources regularly used in primary schools (KiwiDex, KiwiSport), the New Zealand Heart Foundation supplies free posters featuring the food pyramid and other "healthy heart" resources to schools and the Family Planning Association, together with groups like Drug Abuse Resistance Education (DARE) contribute resources on teenage pregnancy and drug and alcohol abuse on request.

The 1985 Health Education in Primary and Secondary Schools syllabus defines health as a state of well-being related to the physical, mental and social dimensions of a person's life. The syllabus rejects a medicalised notion of health where "health" is regarded as simply an "absence of disease" and instead embraces a vision of health education as the "process through which people develop the understandings, skills and motivation to act in a responsible way for their own health and the health of others" (1985: 4). Goal-setting, self-monitoring of progress toward health goals and development of a healthy "attitude" towards one's own health are key emphases in this syllabus. Curriculum content is organised into nine themes: Building Self-Esteem; Eating for Health; Caring for the Body; Physical Activity for Health; Staying Healthy; Keeping Safe; Relating to Others; Finding Out about Helping Agencies; and Having a Role in Community Health Issues. For each of the nine themes, Trial Units were developed to support teaching at each of the school levels. While space prohibits a detailed analysis of each of these resources, it is important to note that many of the imperatives contained within these resources have clearly contributed to the ways in which the year 4 and year 8 students think about health. For example, the New Zealand Heart Foundation's food pyramid, which details recommendations for the type and quantity of food groups that should be ingested, has been the preferred vehicle through which to teach young people about "eating for health". Not only has the "factual" nature of the

\begin{tabular}{|l|}
\hline Deleted: Discourses \\
\hline Deleted: Media \\
Deleted: Syllabi \\
Deleted: Texts
\end{tabular}


pyramid's content been appealing to teachers, but also it is an item that lends itself well to a range of pedagogic possibilities - for example, it can be coloured in, written inside, drawn in, recited, posters can be made and displayed and children can readily be tested on its constituents.

The 1987 Syllabus of Physical Education for Junior Classes to Form 7 replaced the 1953 Primary School Syllabus and has been the legal prescription for New Zealand teachers of physical education in primary sectors until 1999. The syllabus stresses the role physical activity can play in physical development, social and personal development. A large range of specific objectives for physical education is claimed. Included amongst these are claims that physical education programmes can help students to learn to make informed decisions about a healthy lifestyle; develop and maintain physical fitness; to develop self-esteem; to learn to face and respond to challenges; and to develop attitudes and practices for safe participation in physical activities.

\section{Life Education}

The Life Education Trust is the other main source of school-based health education in primary and junior secondary schools in New Zealand, complementing and at times replacing the classroom teacher as a provider of health education. The Life Education Trust is one of several community-based groups working with young people in the sphere of drug education. The Trust's programme originated with the work of Ted Noffs in Sydney and was implemented in New Zealand in 1988. Programme leaders adopt a preventative approach to substance abuse, environmental abuse and social abuse. As the southern region director of the Life Education Trust suggests:

One objective is to provide children in their formative years from five to 12 with an awareness and understanding of their wonderful bodies. They are taught how they function, and why the body is affected by substances that upset its delicate equilibrium. (Murray, 1994, quoted in Dunbar, 1994: 13)

The Life Education Trust has extensive involvement in primary school programmes throughout New Zealand. In the Otago region alone, most primary school classes, from new entrants to form 2 are visited once a year by the mobile classroom ${ }^{2}$ and both children and teachers are supplied with Life Education materials and resources for on-going study. The Life Education Trust programme has tailored its teaching resources to link directly to the aims and objectives of the new Health and Physical Education in the New Zealand Curriculum syllabus. Thus, many primary school teachers find the materials both accessible and applicable to their school-based programmes. Indeed, it would appear that for some schools, Life Education visits are the extent of the health education programme offered.

A resource package is provided for teachers and students when they sign on for Life Education sessions. Curriculum content is compartmentalised into eight age-related levels corresponding to the first eight years of compulsory schooling. Prior to year 4, students enrolled in the Life Education programme will have engaged in activities that include colouring in pictures of fruit, drawing food they should eat to "stay healthy", identifying foods they should eat most of, less often, only occasionally, and naming parts of the breathing system. From level 5 through to level 7, topics like "meals without added sugar, salt and fat" and "three different healthy breakfasts" are illustrative of the continued reiteration of the food theme. In addition, activities addressing the dangers of smoking, drug and alcohol consumption, road accidents, peer pressure, together with topics like making friends and dealing with feelings predominate. At level 8, setting goals, coping with stress, discovering the positive in yourself and the importance of balancing food and exercise, and moderating consumption of "unhealthy" substances is stressed. Some of the specific exercises children are asked to complete include a life expectancy exercise linking longevity to specific forms of employment, eating habits, stress level, weight and exercise; an 
exercise which links character to body shape and several food pyramid and anti-smoking exercises. The pedagogical practices associated with the Life Education Program, like those of the Health and Physical Education Syllabi, thus provide detailed and meticulous instructions for the right conduct to ensure a long, healthy and happy life, together with the means to judge the lives and conduct of others.

\section{Television advertisements}

The media are clearly and profoundly implicated in the process of meaning production around health. The media report on the latest identification and amelioration of risks. They translate and often dramatise the risks or deficiencies of particular groups. In particular young people are constructed as problems, at risk from drugs, obesity and inactivity. They (re)produce notions of individual responsibility and blame. Government media campaigns such as the Hilary Commission's Push Play campaign and television documentaries such as The Cotton Wool Generation validate these discourses and translate them into national concerns. In the Push Play campaign, vignettes of people of different ages, cultures, shapes and sizes are shown using their bodies in everyday ways to emphasise that exercise is not something that necessarily has to be completed at a gym. The Cotton Wool Generation was a New Zealand documentary, screened in November 2000, that suggested the major causes of obesity in children are too much TV watching, too much junk food and not enough exercise, and blamed parents for allowing children to engage in these practices.

Advertisements for commercial weight-reducing programs and products provide another set of resources. While their messages are more explicitly directed at weight loss and improving body shape and appearance, often conflating these with health indicators, they also imply that health is the responsibility of the individual. One of the most prominent is the Jenny Craig Weight Loss Programme. The advertisement for this program emphasises the relationship between losing weight and having a better life. "Before" and "after" photos of women who have participated in the programme are accompanied by voice text that says, "the way I felt then and the way I feel now, well there's just no comparison. It's just a wonderful, happy, shining feeling”. Another advertisement for this program states "it's not about what you eat really it's about how to live your life in a healthy way ... [Jenny Craig has] taught me to like me again”.

In the Bioslim infomercial, consumers explain that losing weight with the assistance of the Bioslim project makes them "feel twenty". The "host" of the infomercial asks "do you love your new body?", and the response from the consumer featured is "Bioslim changed my life". Here, as is the case with the Jenny Craig advertisements, losing weight is equated with gaining a life, with happiness and with success. The advertisement for Fastburner, a "meal replacement formula", claims that Fastburner can help consumers lose weight quickly. It also suggests that losing weight will mean consumers will "look and feel healthier, have more energy, feel stronger and fitter". The notion that weight is a significant "marker" of health is clearly conveyed by in this advertisement.

Advertisements for the products that children are likely to consume as food also provide implicit messages about health and how certain behaviours, i.e. eating these food products, will contribute to health and fitness. For instance in a Nutragrain commercial, an ironman works out amongst metal, fire and steam. The weight stack he is lifting turns in to a dragon that he battles and the text message is "Nutragrain-ironman food". Weetbix is promoted as the "official breakfast of the All Blacks". One of the key components of Weetbix focused on in the advertisement is its low sugar content and high iron content. 
The important point to make here is that these outside school resources confirm and support the central messages of school-based resources, informed as they are by discourses which present health as an individual responsibility and a healthy lifestyle (based on informed health choices related to diet and physical activity) as intimately connected to happiness, attractiveness and moral rectitude

In the next section of the paper we use the students' responses to the NEMP tasks to demonstrate how these discourses are taken up. In our analysis we looked for (and found to a very limited extent) disconfirming evidence of students' use of the dominant health discourses. However, overwhelmingly the responses to the NEMP Healthy Person and Being Healthy tasks demonstrated the prominence of these discourses as knowledge resources for students' interpretations of the meaning of health.

\section{What the students say about health}

\section{Healthy person}

As an introduction to the Healthy Person task, students were each told: "Being healthy means many things to do with what is sometimes called our 'total well-being'. So ... you need to think of everything that helps make a person feel good ... Tell me what you think total well-being means...?" Despite the apparent invitation to nominate the attributes of a healthy person, responses to this task (written in the balloons that were arranged around the figure of a young person) often took the form of exhortations to perform particular actions such as "wash yourself", "drink lots of milk and water, not cordial". This was particularly the case for the year 4 students whose responses tended to be more truncated and often took the form of single words.

In both the year 4 and the year 8 responses to this task it was very rare to find no mention of diet and exercise (or being fit) in one form or another. The references to diet could be as general as eating "healthy food" or a "balanced diet" to the nomination of fruit and vegetables, with specific fruit and vegetables often listed. There were also frequent references to drinking "lots of water". Less often for this task, but still worth noting in terms of the information on which the children were drawing, were the negative directives to not eat or drink certain foods, such as “don't eat too much junk food”, “don't eat much sugar”, “don't eat too much fat”. As will be seen with the responses to the next task, Being Healthy, clear lines were drawn between food that should be eaten and food which was to be avoided. Although only two students explicitly referred to the "food pyramid", the students' responses suggested school-based information on diet and that the information embedded in the "food pyramid" was an important resource for the students - for instance, the preference for fruit and vegetables (and for some cereals as well) and the suggestions to avoid fat and sugar.

References to exercise were expressed in a number of ways from simply writing the word "exercise" to responses such as "getting more fit and being more active" and "a healthy person is a person who is fit". The responses to other tasks in the NEMP project on fitness make it clear that for most of the students fitness is the outcome of physical activity/exercise. In the responses to the Healthy Person task, there were few explicit links made between health and looking good although this relationship again comes through very strongly in the responses to the fitness tasks (see Burrows et al., 2001, for a more detailed discussion). Where there were references to appearance for this task, these were most likely to come from year 8 students and were likely to be realised for this task in comments such as "Think good about yourself. Like your appearance".

What differentiated the year 4 from the year 8 responses (besides the length of their responses and the improved spelling) was more frequent references to smoking, drinking and drugs as in “don't smoke/drink/take drugs" and more frequent references to emotional/affective aspects of 
person's health and the importance of relationships, specifically friends and family. For instance, year 8 students wrote responses such as "not putting yourself down, liking yourself", "being confident in yourself", "healthy in your mind - don't think you are ugly or fat", "keep original, don't try to imitate other people”, “(d)oing things you enjoy and spending time with family and friends", and "being kind and care for others". To provide a sense of the responses, the following examples have been provided. In choosing these examples we have tried to provide for some variation in the nature of the responses - that is, most of the responses were similar to one or other of these examples. The similarity and consistency for each year of the responses to all of the tasks that we analysed was remarkable.

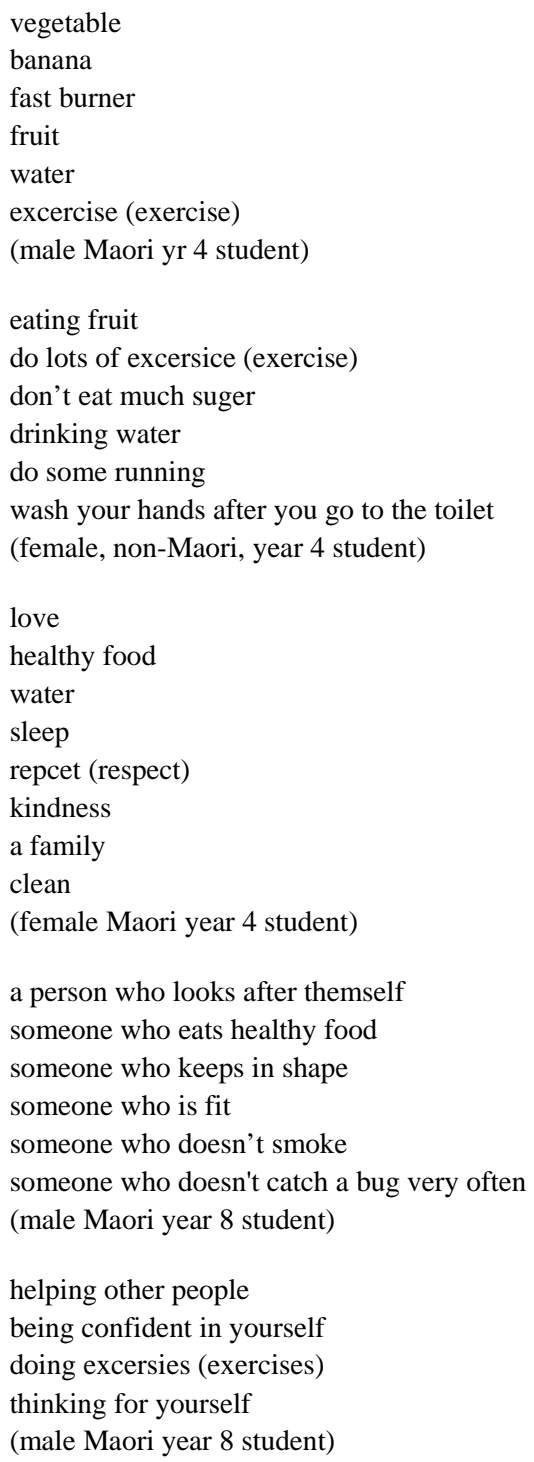


not filling your mind with un-pure things ie violence.

eating healthy things or the right foods.

not abusing your body with drugs alchahol and tabacco.

exercizing (exercising) a lot to keep fit.

washing your self daily ie. shower brushing teeth.

(female non-Maori year 8 student)

\section{Being healthy}

Deleted: Healthy

This was a one-to-one task where the visiting teacher recorded student responses to the question, "what does a person needs to do to be really healthy?" Students were encouraged to think about as many different things as they could and the visiting teacher was instructed to suggest to students that each idea be written down separately even when two or more ideas were given as one. This task explicitly asked children what they could do to be really healthy, that is, what actions or behaviours could they undertake to ensure they would be not simply healthy but really healthy.

Although the prompts for the task were different, the general content of the responses differed little from the Healthy Person task. Because the teacher wrote down the responses they tended to be more detailed. The responses also tended to be more prescriptive and specific. For instance, in the following quote from a year 4 student, amounts of food and water are specified as well as a lengthy set of person health practices - that is, the message implied by the question and taken up with gusto by the students seems to be: follow all of these instructions and you will become a healthy person.

Eat lots of vegetables and fruit.

Eat healthy cereals and toast.

When sick take medicine if you need to.

Get lots of sleep.

Brush your teeth.

Take a bath every night.

Don't smoke.

Drink 8 glasses of water every day.

Don't eat too much food with fat.

Eat 5 vegetables and fruit a day.

(male Maori year 4 student)

Hygiene practices were signalled as important by both year 4 boys and girls. As Mayall (1994) suggests self-care activities like brushing one's teeth, keeping clothes and body clean and washing one's hands, are some of the first "health" lessons learned in the "home" environment with parents often viewing a child's capacity to carry out these tasks independently as a sign of his/her growing maturity and responsibility.

Despite the fact that this question specifically asked students to identify things they could do to promote health many students in year 4 and 8 described behaviours that people should not do, for example, “don't smoke; don’t take drugs”, “don’t eat too much”, “don’t eat sweet things” and "don't sit and watch TV". However for the year 8 responses, the emphasis shifted from predominantly "don't eat this and that" messages to warnings about the dangers of alcohol, smoking and drugs. The Life Education programme material and Health Education Trial Units contain a wealth of material related to risks of drug and alcohol abuse and with the recent release 
of OECD statistics for New Zealand youths' levels of drug and alcohol abuse, government concern about this issue is intense. The Life Education programme, in particular, focuses on educating children about "what is healthy and what is harmful" (Nicholson, 2000).

At year 8 statements about deliberate exercise (of which there were many at year 4) were much more prescriptive. That is, students were specific about not only what exercise should be undertaken but how much of it should be done. For example, "run two times per day" and "exercise a lot". Going to the gym was frequently recommended as a means to health by both year 4 and year 8 students.

While year 4 students' responses suggested that eating healthy foods was crucial, in year 8, like exercise, the responses become a lot more prescriptive. For example, "vitamins" were mentioned more often together with statements like "eat for protein". The language of "moderation" was also more apparent in the year 8 responses. For example "don't have too many lollies", "good eating-flow, sometimes spoil yourself but not too often") and sometimes in explicit statements like "take everything in moderation" or "watch what you eatmoderation". The food pyramid was mentioned slightly more often in year 8, however the prescriptions concerning food continue to reflect even more closely school-based learning about diet. One student had clearly absorbed the message being conveyed by an extensive Heart Foundation television advertising programme. She equated eating well with eating "foods that have the national heart label".

The year 8 responses were much more likely to include references to enjoying life, being "Being open-letting your feelings out", "happy on the inside" and having a "friendly_healthy mind", to avoiding stress "don't let stress get to you", "relax-try (not) to get uptight" and to interpersonal relationships "have friends around to tell nice things"; "be kind to others"; "be friendly to others so not just healthy physically”.

The following quotes are illustrative of these themes. Again they are typical of the range of responses from the year 4 and year 8 students. The specific recommendations (e.g. buy a treadmill) may have differed but the inclusion of some recommendation concerning exercise and eating could be regarded as almost universal.

Healthy food - fruit veges, bit of meat.

Daily exercise.

A run.

A bike ride.

A swim.

Rest.

Try to keep off fat foods like pies and icecream.

Not too much butter on bread.

Even if you don't eat healthy food exercise can get rid of that.

(year 4 male, Maori student)

Don't eat sweets/chocolates/lollies.

Go to the gym a couple of days a week.

Go and run sometimes.

Only eat the food in the bottom of the food pyramid (vegies)

Try going to the doctor if you feel sick.

When you go outside use sun lotion and a hat.

Don't drink out of cups that other people have been using.

Try and get some fresh air.

Drink lots of fluid. 


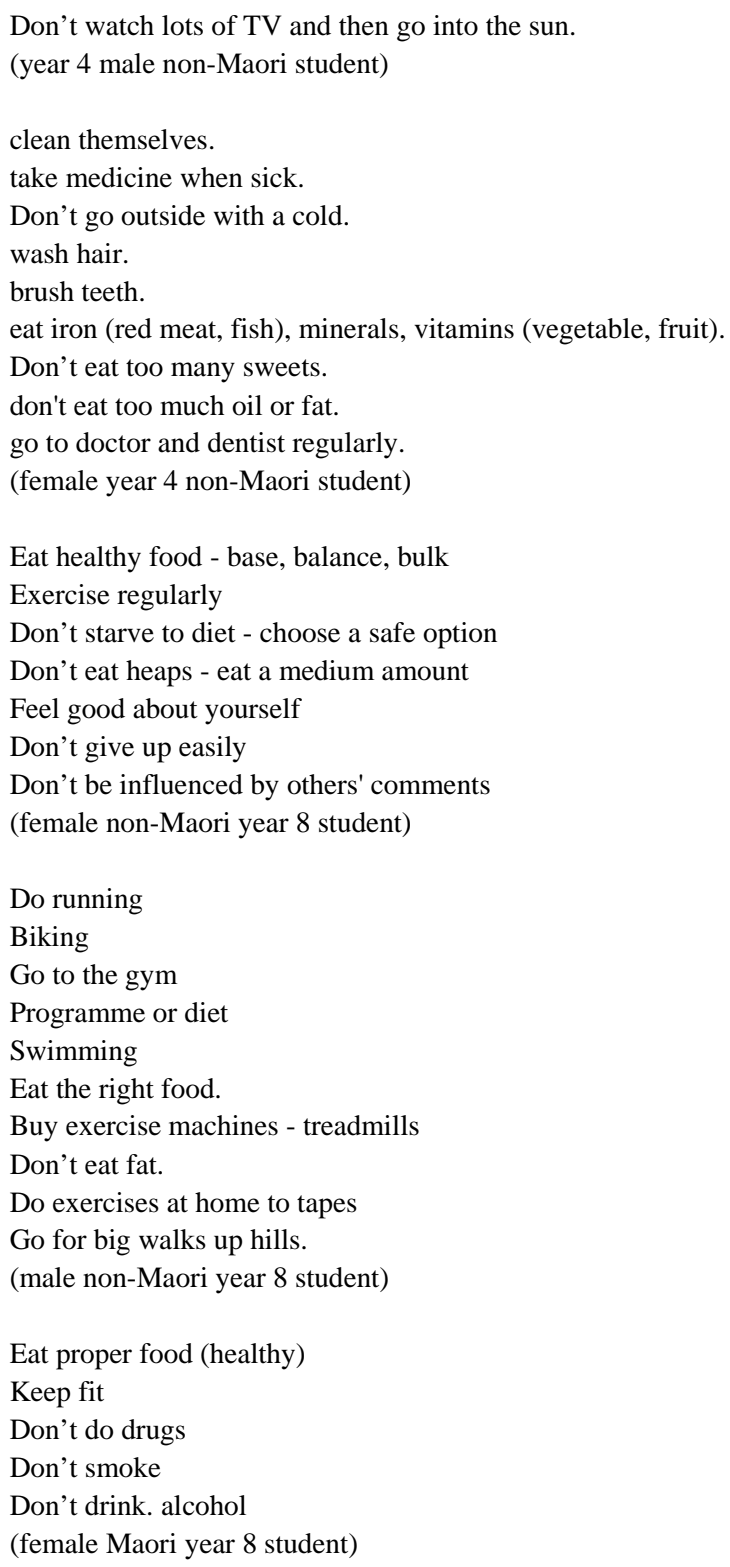

\section{Discussion}

The students' responses to the NEMP tasks seem to indicate a combination of family health talk and school-based health education which focused on personal care. For example, statements like "wash your hands before you eat”, "clean your body with hard scrubs" and "always wash your 
hair" are lessons regularly taught in the home (Mayall, 1994). Personal care practices like avoiding smoking, drinking and drugs, and adopting very specific dietary habits and exercise regimes may be suggested in home environments. Given the specificity of information conveyed in responses, however, it is likely that many of these imperatives have been drawn from schoolbased health and physical education classes. In general, more extended, detailed and arguably holistic notions of health were expressed by the year 8 students as compared to the year 4 students. Where do these different responses come from? Are they simply a result of "developmental" maturity-the cognitive advances "expected" of year 8 students? Following Morss (1996), Walkerdine (1984) and Burman (1991), we would argue that developmentalism is an unsatisfactory explanation for the differences noted between the two year groups. Rather, the question we ask is what discursive resources do these students draw on to make sense of health in this way and with what consequences? What alternative constructions of health are possible? And what are the consequences of such discourses for the ways in which children and young people come to understand themselves and the "proper" conduct of their lives?

On the one hand, the health promotion proponents should be pleased by the results reported in this paper. If knowledge leads to appropriate behaviour, it could be said that this group of New Zealand students know the prescription for good health in terms of eating and physical activity and as they get older they also know that it is unhealthy to use alcohol, tobacco and other drugs. Many of the older students seem also to have interpellated understandings about the relationship between self-esteem/self-confidence and health and the importance of a supportive and caring family as espoused by school-based and Life Education health programs.

In other words, the students are well-versed in healthism discourses which link personal practices associated with the body-specifically eating and exercise but also smoking, drinking and taking drugs - with "health". As they move through school, they become more adept at drawing on this discourse. The assumption on which their answers to the NEMP questions are based is that individuals who eat healthy food, exercise regularly and consistently and who avoid alcohol, tobacco and drugs will be healthy people. Acknowledging that the students' responses have been collected in a school-based exercise designed to determine what they know, the consistency of their responses still speaks to the efficacy of the school and the Life Education materials, supported by family and media messages, as technologies of the self, whereby students come to know how to engage in the work on their bodies necessary to become healthy citizens and thereby live the good life.

In this account of the responsible healthy citizen no attention is paid to the social, economic or political contexts of people's lives, nor to the complexities which lie behind notions of "healthy food", "exercise" and indeed the consumption of alcohol, tobacco and other drugs. The representation of Maori and non-Maori students in the study parallels that in New Zealand society more generally, yet little attention is paid to other constructions of health that may be more meaningful to cultural groups other than the white middle-class, nor to broader notions of health which would prioritise other aspects of health such as connectedness to community, respect for elders over a preoccupation with personal health issues. There were alternative constructions of health evident among students' responses-although in the corpus available to us these were very rare. For instance, both the following responses are from Maori students from different schools, the first from a year 4 male Maori student and the second from a year 4 female Maori student.

Kai i nga hua kau menga hua whenua (Eat fruit \& vegetables)

Aroha Ki te tahi (Love one another)

Whakaro rongati ra (Respect your elders)

hongi i nga rangati (Greet your elders) 
awhina i a rutau (Take care of elders)

Kawa e whakatoi (Don't be cheeky/stubborn/obstinate)

(year 4 male Maori)

Omaoma (Running)

Moe Kapai manaki ohoa pumau (Take care of your friends)

Whakaro rangatina (Be considerate)

Me kai Parakuihi iaraiara. (Eat breakfast every day).

Takaro me ohoa hoa tukai. (Play)

kaputi mairou (Drink tea and milo)

Moe (Sleep)

Kauae whakaito (Don’t be cheeky)

Manaki o kuia koroua (Look after your elders)

(year 4 female Maori)

Such responses help to remind us that those responses taken as typical of the corpus and discussed in the main body of the paper are evidence of specific socially constructed meanings and values about health. The "typical" responses are evidence of the dominance of white, middle class values about health and fitness promoted in New Zealand society. The cultural base from which Maori notions of health and wellbeing are derived is at odds with the values embodied in most of the responses. In New Zealand, Maori constructions of health have to some extent been taken up in the writing of the new syllabus for Health and Physical Education. For example, Mason Durie's (1994) whare tapawha is used to point to a model of health (hauora) that compares wellbeing to the four walls of a whare (house). Taha tinana (the physical dimension), taha hinengaro (the mental dimension), taha whanau (the family dimension and taha wairua (the spiritual dimension) represent the four walls, each of which is integral and interrelated to the achievement of a balanced and harmonic whole. The extended family is considered to be integral to health and well-being) - a notion that contrasts with the individualistic conceptions of health advanced within school contexts. Whether this serves to expand the repertoires of health meanings available to young people in New Zealand schools remains to be seen.

\section{Issues about how the knowledge gets constructed as certain}

What is also evident from the corpus of responses is the consistency with which particular biomedical "truths" about health and the body were reiterated. The students provide evidence of the ways in which knowledge which is recontextualised from bio-medical research is transformed into simplistic "facts". This is in opposition to knowledge which is presented as uncertain, constructed knowledge which is constantly being reviewed and revised. Such apparent certainty does not serve children or people well. People are presented with contradictory knowledge on a daily basis. They see relatives who smoke and live until 80 years old; they see people who exercise daily and die at 45; they see people who eat fatty food and never put on weight. How are students and people generally to make sense of such inconsistencies? What resources does schooling provide to deal with uncertainty?

Working from the assumption of certain knowledge is inappropriate on a number of counts. Firstly, the knowledge that children are presented with in school is already contested on many fronts. For example, the constituents of the food pyramid are being revised, the amount, intensity and type of exercise required to maintain "fitness" has undergone several revisions and the 
epidemiological studies from which "facts" about diet and exercise, obesity and ill-health have been drawn are being critiqued (Gard \& Wright, 2001). Secondly, the process by which knowledge about health is presented in school health and physical education programmes inducts students into a world which assumes "certainty", instead of preparing students to evaluate knowledge, to recognise "expert" knowledge as uncertain and transitory and encourage them to form an active relationship with knowledge. Students need to learn to become inquirers, to develop tools to work with uncertain knowledge which do not immobilise or cause fear and anxiety but which allow for action and choice. Current health imperatives leave little room for engagement with health knowledge. Rather, so-called critical enquiry becomes a matter of selecting the "right" response or behaviour from a limited range of possibilities etc. As argued above it serves the purposes of governmentality rather than a socially informed understsanding of the constructedness of health knowledge.

The new senior syllabi in health and physical education in New Zealand schools does provide some room for such a critical approach. There is substantially more encouragement to "analyse societal influences that shape community health goals and physical activity patterns" (Ministry of Education, 1999: 65) and subject orthodox understandings to critical scrutiny. At least rhetorically the new syllabus expects students to engage in critical inquiry and to examine the meanings of health and physical activity as social constructions. Neither syllabus, however, references this specifically to challenging taken-for-granted truths of bio-medical research. The questions remain as to whether teachers themselves are sufficiently prepared to challenge the certainty of the bio-medical knowledge and the constructions of youth at risk (Wyn \& White, 1997) which have underpinned their own preparation for teaching and which continue to be powerful public discourses in physical education teacher education. Questions remain which are not within the scope of this paper but which need to be explored if the issues raised here are to be moved into practice. Questions such as: what is required to assist students and the public to deal with the uncertainty which such changed practices might produce, and what pedagogical tools are necessary to not only question taken-for-granted truths (I think we have these) but to deal with the anxiety that this might indeed produce?

\section{NOTES}

1 Maori are the indigenous peoples of New Zealand. Maori have models of health incorporating values and assumptions that differ from some western notions of health. While some Maori children attend Kura Kaupapa Maori schools conducted in Te Re Maori (Maori language and in accordance with Maori-preferred pedagogies), over $90 \%$ of Maori children are still located in regular state schools.

${ }^{2}$ n 1999, $97.4 \%$ of primary schools had been visited at least once by the Life Education truck (Nicholson, 2000).

\section{References}

Bacchi, C. (2000). Policy as Discourse: What does it mean? Where does it get us? Discourse, 21(1), 45-58.

Burman, E. (1991). Power, gender and developmental psychology, Feminism \& Psychology, 1(1), 141-153.

Burrows, L., Wright, J. \& Jungersen-Smith, J. (2001). 'Look in the mirror and see how strong your muscles are...' New Zealand children's constructions of health and fitness. A paper presented at the American Education Research Association Annual Meeting, Seattle.

Castel, R. (1991). From dangerousness to risk. In: G. Burchell, C. Gordon \& P. Miller (Eds) The Foucault Effect: studies in 
governmentality. Hempel Hempstead: Harvester Wheatsheaf.

Crooks, T. \& Flockton, L. (1999) Health \& Physical Education: assessment results 1998. Dunedin: University of Otago Educational Assessment Research Unit.

Davis, P. \& Dew, K. (Eds) (1999). Health and Society in Aotearoa New Zealand. Auckland: Oxford University Press.

Department of Education (1986/1987). Health Education Trial Unit for Designated Schools. Wellington: Department of Education.

Department of Education (1985). New Zealand Health Education Syllabus. Wellington: Department of Education.

Department of Education (1987). Physical Education: Syllabus for junior classes to Form 7 with guidelines for early childhood education. Wellington: Department of Education.

Dunbar, A. (1994). Addiction to life instead of drugs. The Press (Christchurch), Tuesday 28 June, 13.

Durie, M. (1994). Whaiora: Maori health development. Auckland: Oxford University Press.

Foucault, M. (1977/1988). Discipline and Punish: The birth of the prison. London: Penguin.

Gard, M. \& Wright, J. (2001). Managing uncertainty: obesity discourses and physical education in a risk society, Studies in Philosophy and Education, 20(6), 535-549.

Gore, J. (1993). The Struggle for Pedagogies: Critical and feminist discourses as regimes of truth. Sydney: Routledge.

Gore, J. (1995). On the continuity of power relations in pedagogy, International Studies in the Sociology of Education, 5(2), 165-188.

Ministry of Education (1999). Health an Physical Education in the New Zealand Curriculum. Wellington: Learning Media. Deleted: HPE curriculum,

Kelly, P. (1998). Risk and the regulation of youth(ful) identities in an age of manufactured uncertainty, Unpublished Formatted doctoral thesis, Geelong, Deakin University.

Kirk, D. and Colquhoun, D. (1989). Healthism and physical education. Bitish Journal of Sociology of Education, 10(4), 417434.

Lupton, D. (1995/1999) The Imperative of Health: public health and the regulated body. Sage: London).

Mayall, $\mathrm{B}_{\mathbf{r}}(1994)$. Children, Health and the Social Order. Buckingham: Open University Press. $\checkmark$

Morss, J. (1996). Growing Critical: Alternatives to developmental psychology. London: Routledge.

Murray, M. (1994). Quoted in Dunbar, A. Addiction to life instead of drugs. Report in Fitness \& Health on Tuesday, June 28, 1994, 13.

Nicholson, L. (2000). Personal communication, November.

Petersen, A. R. (1996). Risk and the regulated self: the discourse of health promotion as politics of uncertainty, ANZJS, 32(1), 44-57.

Seedhouse, D. (1997). Health promotion: philosophy, prejudice and practice. New York: Wiley.

Sparkes, A. C. (1989). Culture and ideology in physical education. In: T. Templin \& P. Schempp (Eds) Socialization into Physical Education: Learning to teach. Indianapolis: Benchmark Press.

Tinning, R. (1985). Physical education and the cult of slenderness: a critique, The ACHPER National Journal, 10(7) (Autumn), 10-13.

Walkerdine, V. (1984). Developmental psychology and the child-centred pedagogy: The insertion of Piaget into early education. In: W. Hemriques, C. Holloway, C. Urwin, C. Venn, \& V. Walkerdine (Eds) Changing the Subject: psychology, social regulation and subjectivity. London: Methuen.

Williams, S. J. \& Bendelow, G. A. (1998). Children's beliefs about health, cancer and risk. In: S. Nettleton \& J. Watson (Eds) The Body in Everyday Life. London: Routledge.

Wyn, J. \& White, R. (1997). Rethinking Youth. Sydney: Allen \& Unwin. 